\title{
Perbandingan Parasetamol dengan Ketorolak Intravena Sebagai Analgesia Pre-emtif terhadap Skala Nyeri Pascabedah Labioplasti pada Pasien Pediatrik
}

\author{
Muhamad Adli Boesoirie, ${ }^{1}$ Ezra Oktaliansah, ${ }^{2}$ Tatang Bisri ${ }^{2}$ \\ ${ }^{1}$ Departemen Anestesiologi dan Terapi Intensif Fakultas Kedokteran Unpad/Pusat Mata Nasional \\ Rumah Sakit Cicendo, ${ }^{2}$ Departemen Anestesiologi dan Terapi intensif \\ Fakultas Kedokteran Universitas Padjadjaran/Rumah Sakit Dr. Hasan Sadikin Bandung
}

\begin{abstract}
Abstrak
Parasetamol dan ketorolak merupakan analgetik yang biasa digunakan pada tatalaksana nyeri ringan hingga sedang. Penelitian ini bertujuan membandingkan efek analgesi pre-emtif parasetamol $20 \mathrm{mg} / \mathrm{kgBB}$ dengan ketorolak $0,5 \mathrm{mg} / \mathrm{kgBB}$ pada pasien pediatrik pascabedah labioplasti yang diukur menggunakan skala nyeri face, legs, activity, crying, consolability (FLACC). Penelitian eksperimental secara uji acak tersamar buta ganda terhadap 66 pasien pediatrik usia 6 bulan-12 tahun dengan status fisik American Society of Anesthesiology (ASA) I-II. Penelitian dilakukan di Rumah Sakit Dr. Hasan Sadikin Bandung periode Oktober 2013-Mei 2014. Pasien dibagi menjadi dua kelompok perlakuan, yaitu kelompok parasetamol (P) dan ketorolak (K) yang diberikan 15 menit prabedah. Analisis statistika diuji menggunakan uji-t independen, Mann-Whitney, dan Eksak Fisher. Hasil penelitian menunjukkan bahwa skala FLACC pada kelompok ketorolak pada jam ke-1, $2,4,6$, dan 24 lebih rendah secara bermakna $(\mathrm{p}<0,05)$ dibanding dengan kelompok parasetamol. Simpulan, skala FLACC pemberian ketorolak $0,5 \mathrm{mg} / \mathrm{kgBB}$ prabedah pada pasien labioplasti lebih rendah dibanding dengan parasetamol $20 \mathrm{mg} / \mathrm{kgBB}$.
\end{abstract}

Kata kunci: Analgetik, analgesia pre-emtif, ketorolak, labioplasti, parasetamol, skala FLACC

\section{Comparison between Intravenous Paracetamol and Ketorolac as Preemptive Analgesia on Postoperative Pain Scale in Pediatric Patients Undergo Labioplasty}

\begin{abstract}
Ketorolac and paracetamol are common analgetics used to treat mild to moderate pain. This study compared the efficacy of preemptive analgesia measured using face, legs, activity, crying, consolability (FLACC) scale between groups receiving $20 \mathrm{mg} / \mathrm{kgBW}$ paracetamol (P) and $0.5 \mathrm{mg} / \mathrm{kgBW}$ ketorolac (K) for pediatric labioplasty procedure. This experimental study is a are double-blind randomized trial against 66 pediatric patients aged 6 months-12 years with the physical status of the American Society of Anesthesiology (ASA) I-II. The study was conducted in Dr. Hasan Sadikin General Hospital Bandung during the period of October 2013-May 2014. The P and K groups received $20 \mathrm{mg} / \mathrm{kgBW}$ paracetamol and $0.5 \mathrm{mg} / \mathrm{kgBW}$ ketorolac, respectively, 15 minutes preoperatively. Data were analyzed statistically using independent-t, Mann-Whitney, and Fischer's Exact Test. Results showed that the difference between FLACC scale in P and K groups was statistically significant $(\mathrm{p}<0.05)$. In conclution, FLACC scale in patients who received ketorolac $0.5 \mathrm{mg} / \mathrm{kgBW}$ is lower than patients who received paracetamol $20 \mathrm{mg} / \mathrm{kgBW}$.
\end{abstract}

Key words: Analgetics, FLACC scale, ketorolac, labioplasty, paracetamol, preemptive analgesia

Korespondensi: Muhamad Adli Boesoirie, dr., SpAn, Departemen Anestesiologi dan Terapi Intensif Fakultas Kedokteran Universitas Padjadjaran Pusat Mata Nasional RumahSakitCicendo,Jl.Pasteur No.38Bandung 40161,Mobile08122107949, Emailmuhamad.adli.b@gmail.com 


\section{Pendahuluan}

Nyeri menurut International Association for the Study of Pain (IASP) adalah pengalaman sensoris dan emosional tidak menyenangkan yang berhubungan dengan kejadian kerusakan jaringan. Pada bayi maupun anak yang belum dapat berbicara sulit untuk dapat menjelaskan nyeri yang dialaminya. Keadaan ini sering kali menimbulkan interpretasi yang keliru akan nyeri yang dialami oleh pasien kelompok pediatrik. Tujuan utama penilaian nyeri adalah memberikan data-data yang akurat mengenai lokasi dan intensitas nyeri, serta memberikan efektivitas dalam tatalaksana nyeri. ${ }^{1}$

Skala perilaku face, legs, activity, cry, consolability (FLACC) dapat digunakan untuk penilaian nyeri pada anak yang belum dapat berbicara, dewasa dengan keterbelakangan mental, serta dewasa dengan sakit kritis. Setiap kategori perilaku diberikan nilai 0-2 dengan jumlah nilai minimum 0 dan nilai maksimum 10. Interpretasi nyeri pada skala FLACC sesuai dengan NRS, yaitu " 0 " menandakan tidak nyeri dan "10" menandakan sangat nyeri. ${ }^{2}$

Analgesia pre-emtif adalah suatu tindakan pemberian analgetik sebelum terjadi stimulus nyeri yang bertujuan mencegah sensitisasi sistem saraf pada suatu rangsangan yang dapat mengamplifikasi nyeri. Tindakan pembedahan merupakan suatu keadaan yang tepat untuk penerapan analgesia pre-emtif karena dapat diprediksi kapan suatu stimulus nyeri akan terjadi. $^{3}$

Parasetamol merupakan golongan sintetik nonopioid yang bekerja sebagai analgetik dan juga antipiretik sentral yang merupakan turunan dari p-aminofenol. Parasetamol tidak memengaruhi fungsi trombosit, perdarahan akibat pembedahan maupun fungsi ginjal, oleh karena itu parasetamol sangat sesuai untuk penggunaan perioperatif. Saat ini parasetamol secara resmi direkomendasikan oleh American Society of Anesthesiologists (ASA) sebagai lini pertama dari komponen analgesia multimodal untuk tatalaksana nyeri pascabedah. ${ }^{4}$

Ketorolak adalah suatu obat anti-inflamasi nonsteroid (OAINS) yang bekerja menghambat sintesis prostaglandin. Sama halnya dengan parasetamol, ketorolak juga merupakan obat yang biasa dipergunakan sebagai tatalaksana nyeri yang ringan hingga sedang. Pemberian ketorolak dapat mengurangi penggunaan opioid sehingga menurunkan angka kejadian efek samping yang berhubungan dengan pemberian opioid. Beberapa hasil penelitian menunjukkan bahwa ketorolak memiliki efek analgesia pre-emtif. ${ }^{5}$

Labioplasti adalah tindakan pembedahan untuk mengoreksi kelainan bawaan berupa celah pada bibir. Insidensi celah bibir adalah 1:7.500 pada ras Kaukasia dan lebih tinggi pada orang Asia. Skala nyeri yang ditimbulkan akibat tindakan pembedahan ini adalah "4" atau termasuk skala nyeri kategori sedang. ${ }^{6}$ Tatalaksana nyeri pada tindakan labioplasti sering kali diberikan melalui rute/jalur oral ataupun rektal. ${ }^{6}$ Penelitian ini bertujuan untuk mengkaji perbandingan skala FLACC pascabedah labioplasti pediatrik pada pasien yang diberikan parasetamol $20 \mathrm{mg} / \mathrm{kgBB}$ intravena prabedah dengan ketorolak $0,5 \mathrm{mg} /$ kgBB intravena prabedah.

\section{Subjek dan Metode}

Penelitian dilakukan di Instalasi Bedah Sentral elektif lantai tiga dan empat, Rumah Sakit Umum Pusat Dr. Hasan Sadikin, Jl. Pasteur No. 38, Bandung sejak bulan Oktober 2013-Mei 2014. Penelitian eksperimental secara uji acak tersamar buta ganda dilakukan terhadap 66 pasien pediatrik berusia enam bulan hingga 12 tahun dengan status fisik American Society of Anesthesiology (ASA) I-II. Subjek pada penelitian ini adalah semua pasien pediatrik yang akan menjalani labioplasti yang telah memenuhi kriteria penelitian. Besar sampel ditentukan berdasarkan rumus perbedaan proporsi efektivitas tindakan, dengan memilih tingkat kepercayaan $(\alpha)$ 95\% dan besarnya uji kekuatan $(\beta)$ 80\% sehingga didapatkan jumlah sampel 30 untuk setiap kelompok perlakuan. Kriteria inklusi yaitu pasien pediatrik berusia 6 bulan sampai dengan 12 tahun yang akan dilakukan pembedahan labioplasti serta pasien dengan status fisik ASA I dan II. Kriteria eksklusi yaitu pasien dengan kontraindikasi 
pemberian parasetamol (alergi, gangguan fungsi hati, atau gangguan fungsi ginjal), pasien dengan kontraindikasi pemberian ketorolak (alergi, gangguan fungsi ginjal, pemanjangan faktor koagulasi), dan juga pasien yang sudah diberi obat anti-inflamasi maupun analgetika lain dalam waktu 12 jam prabedah. Penelitian ini mempergunakan uji acak klinis terkontrol tersamar buta ganda (double blind randomized controlled trial).

Setelah mendapatkan persetujuan dari Komite Etik Penelitian Kesehatan Rumah Sakit Umum Pusat Dr. Hasan Sadikin Bandung, dilakukan penjelasan kepada orangtua subjek penelitian mengenai penelitian yang akan dilakukan serta menandatangani persetujuan (imformed consent). Randomisasi dilakukan memakai tabel blok permutasi, lalu sampel dibagi menjadi dua kelompok perlakuan. Kedua kelompok perlakuan tersebut diberikan premedikasi memakai midazolam $0,2 \mathrm{mg} /$ kgBB intramuskular prabedah. Setelah pasien mengantuk atau tertidur, pasien dimasukkan ke dalam kamar bedah. Selanjutnya, dilakukan pemantauan dengan cara memasang monitor standar dan dicatat laju nadi, laju napas, serta saturasi oksigen perifer prabedah.

Induksi anestesia dilakukan menggunakan isofluran yang dinaikkan bertahap mulai 0,22 vol\%, oksigen $50 \%$ dan $\mathrm{N}_{2} \mathrm{O} 50 \%$ melalui sungkup muka. Setelah pasien teranestesia, dilakukan pemasangan infus dengan ukuran kateter vena nomor $24 \mathrm{G}$, kemudian diberikan infus cairan Ringer laktat sesuai kebutuhan cairan. Selanjutnya, diberikan pelemas otot atrakurium 0,5 mg/kgBB dan fentanil $2 \mu \mathrm{g} /$ kgBB, kemudian dilakukan intubasi dengan pipa endotrakea. Rumatan anestesi dilanjutkan dengan isofluran 1,5-2 vol\%, oksigen $50 \%$, dan $\mathrm{N}_{2} \mathrm{O} 50 \%$. Sebelum dilakukan sayatan bedah, kelompok perlakuan I diberikan parasetamol $20 \mathrm{mg} / \mathrm{kgBB}$ secara intravena. Penyayatan bedah dilakukan 15 menit setelah selesai pemberian parasetamol intravena. Kelompok perlakuan II diberikan ketorolak 0,5 mg/ $\mathrm{kgBB}$ secara intravena. Penyayatan dilakukan 15 menit setelah selesai pemberian ketorolak intravena.

Selama pembedahan dilakukan monitoring tekanan darah, laju nadi, dan saturasi oksigen sesuai dengan standar. Setelah napas spontan muncul, dilakukan ventilasi bantuan (assisted ventilation). Pada saat ventilasi spontan sudah adekuat, pasien diekstubasi, lalu dibawa ke ruang pemulihan. Orangtua pasien dihadirkan untuk mendampingi pasien. Pada saat pasien telah sadar penuh dilakukan penilaian nyeri pascabedah menggunakan skala FLACC.

Pada saat pemantauan pasien di ruang pemulihan, bila skala FLACC lebih dari "4" diberikan petidin $0,5 \mathrm{mg} / \mathrm{kgBB}$ intramuskular sebagai analgetika pertolongan. Selanjutnya, di ruang perawatan pemantauan dilakukan pada jam ke-4, 6, 12, dan 24 pascabedah. Pada kelompok perlakuan I, analgetika rumatan parasetamol $20 \mathrm{mg} / \mathrm{kgBB}$ intravena diberikan setiap 6-8 jam setelah pemberian pertama kali pada saat prabedah. Pada kelompok perlakuan II, analgetika rumatan ketorolak $0,5 \mathrm{mg} / \mathrm{kgBB}$ intravena diberikan setiap 6-8 jam setelah pemberian pertama kali pada saat prabedah hingga maksimum 2 hari pascabedah. Analisis statistika data hasil penelitian menggunakan uji-t, Uji Mann-Whitney, dan Uji Eksak Fisher dengan statistical product and servise solution (SPSS) 20.0 for windows.

\section{Hasil}

Penelitian ini dilakukan terhadap 66 pasien pediatrik dengan status fisik American society of Anesthesiologist (ASA) I-II yang menjalani labioplasti dengan anestesi umum di COT lantai 3 dan 4 Rumah Sakit Umum Pusat Dr. Hasan Sadikin Bandung. Setiap kelompok terdiri atas 33 subjek penelitian. Setelah dibandingkan secara statistika pada derajat kepercayaan 95\%, tidak terdapat perbedaan karakteristik usia serta berat badan secara bermakna pada kedua kelompok ( $\mathrm{p}=0,052$; Tabel 1$)$.

Rentang skala FLACC secara keseluruhan pada kelompok parasetamol $20 \mathrm{mg} / \mathrm{kgBB}$ adalah 0-5 dan pada kelompok ketorolak 0,5 $\mathrm{mg} / \mathrm{kgBB}$ adalah 0-4. Berdasarkan hasil uji statistika diketahui bahwa skala FLACC kedua kelompok pada waktu T1, T2, T4, T6, T12, dan T24 berbeda secara bermakna $(\mathrm{p}<0,05$; Tabel 2). 
Tabel 1 Karakteristik Umum Subjek Penelitian Kedua Kelompok Perlakuan

\begin{tabular}{lccc}
\hline & \multicolumn{2}{c}{ Kelompok } & \multirow{2}{*}{ Nilai p } \\
\cline { 2 - 3 } & $\mathbf{P}$ & $\mathbf{K}$ & \\
\hline Usia (bulan) & & $15,64(12,57)$ & $0,052^{*}$ \\
$\quad$ Rata-rata (SD) & $10,27(5,96)$ & $6-72$ & \\
$\quad$ Rentang & $6-24$ & & $0,102^{*}$ \\
Berat badan (kg) & & $8,23(2,21)$ & \\
$\quad$ Rata-rata (SD) & $7,16(1,43)$ & $5,5-21$ & \\
Rentang & $5-10,5$ & & \\
\hline
\end{tabular}

Keterangan: *) Independent t-test

Pada kelompok P, hanya 2 dari 33 subjek yang mendapatkan analgetik pertolongan, sedangkan pada kelompok K hanya 1 dari 33 subjek. Perbandingan analgetik pertolongan antara kedua kelompok tidak bermakna secara statistika ( $>00,05$; Tabel 3).

\section{Pembahasan}

Pencegahan nyeri dengananalgesiamultimodal atau analgesia pre-emtif menunjukkan angka keberhasilan yang cukup memuaskan hampir pada semua kasus nyeri akut dan juga dapat dipergunakan pada semua kasus bedah rawat jalan, pembedahan mayor, pasien anak sakit kritis, dan juga pada bayi. ${ }^{7,8}$ Analgesia pre-emtif merupakan suatu tindakan tatalaksana nyeri yang dimulai sebelum tindakan pembedahan dengan tujuan mengurangi sensitisasi jalur nyeri perifer dan juga sentral akibat tindakan pembedahan. Tindakan "protektif" terhadap sistem nosiseptif pada tatalaksana analgesia pre-emtif lebih efektif jika dibanding dengan tatalaksana nyeri yang dilakukan pada saat pascabedah. Secara teoritis, tindakan analgesia pre-emtif akan mengurangi nyeri pascabedah dan mencegah kejadian nyeri kronik. ${ }^{9}$

Parasetamol merupakan golongan sintetik non-opioid yang bekerja sebagai analgetik dan antipiretik sentral yang merupakan turunan dari p-aminofenol. Parasetamol bekerja secara sentral dengan cara menghambat sintesis prostaglandin dan juga enzim siklooksigenase, serta penghambatan transmisi sinyal melalui sistem serotogenik desenden pada sumsum tulang belakang. ${ }^{10,11}$

Ketorolak merupakan analgetik poten yang termasuk golongan anti-inflamasi nonsteroid

Tabel 2 Perbandingan Skala FLACC antara Kedua Kelompok

\begin{tabular}{|c|c|c|c|c|c|}
\hline \multirow{3}{*}{ Waktu Pengukuran } & \multicolumn{4}{|c|}{ Kelompok } & \multirow{3}{*}{ Nilai p } \\
\hline & \multicolumn{2}{|c|}{$P(n=33)$} & \multicolumn{2}{|c|}{$K(n=33)$} & \\
\hline & Mean & Rentang & Mean & Rentang & \\
\hline $\mathrm{T}_{1}$ & 2,12 & $0-5$ & 1,55 & $0-4$ & 0,002 \\
\hline $\mathrm{T}_{2}$ & 2,24 & $0-4$ & 1,61 & $1-3$ & 0,000 \\
\hline $\mathrm{T}_{4}$ & 2,73 & $2-4$ & 2,15 & $1-4$ & 0,000 \\
\hline $\mathrm{T}_{6}$ & 2,18 & $2-4$ & 1,88 & $1-3$ & 0,002 \\
\hline $\mathrm{T}_{12}$ & 2,00 & $2-3$ & 1,73 & $1-3$ & 0,004 \\
\hline $\mathrm{T}_{24}$ & 1,58 & $1-2$ & 1,18 & $1-2$ & 0,001 \\
\hline
\end{tabular}

Keterangan: T1=jam ke-1, $\mathrm{T}_{2}=$ jam ke-2, dan seterusnya. Nilai $\mathrm{p}$ dihitung berdasarkan Uji Mann-Whitney. Nilai $\mathrm{p}$ bermakna jika $\mathrm{p}<0,05$ 
Tabel 3 Perbandingan Pemakaian Analgetik Tambahan antara Kedua Kelompok

\begin{tabular}{lccc} 
& \multicolumn{2}{c}{ Kelompok } & \multirow{2}{*}{ Nilai p } \\
\cline { 2 - 3 } & $\mathbf{P}(\mathbf{n}=\mathbf{3 3})$ & $\mathbf{K}(\mathbf{n}=\mathbf{3 3})$ & \\
\hline Tanpa analgetik pertolongan & 31 & 32 & 0,500 \\
Dengan analgetik pertolongan & 2 & 1 & \\
\hline
\end{tabular}

Keterangan: nilai p dihitung berdasarkan Uji Eksak Fisher. Nilai p bermakna jika $(p<0,05)$

yang mempunyai efek anti-inflamasi sedang yang bekerja dengan cara menghambat enzim cyclooxygenase (COX) nonselektif. ${ }^{12}$ Berbeda dengan OAINS, parasetamol tidak mempunyai aktivitas substansi anti-inflamasi perifer. ${ }^{4}$ Obat anti-inflamasi nonsteroid sangat bermanfaat pada tatalaksana nyeri pascabedah karena tindakan pembedahan selain menyebabkan nyeri juga dapat mengakibatkan inflamasi pascabedah. ${ }^{13}$ Skala FLACC antara kedua kelompok perlakuan berdasarkan statistika menunjukkan perbedaan bermakna, namun apabila dinilai secara klinis maka skala FLACC antara kedua kelompok perlakuan sebenarnya memiliki kualitas nyeri dalam rentang yang sama yaitu nyeri ringan.

Hasil penelitian ini menunjukkan bahwa skala FLACC pada kelompok $\mathrm{K}$ memberikan hasil berbeda bermakna terhadap kelompok $\mathrm{P}$. Keadaan ini dimungkinkan kerena mekanisme kerja ketorolak sebagai analgetik golongan anti-inflamasi nonsteroid yang akan menekan reaksi inflamasi yang terjadi saat pascabedah sebagai penyebab nyeri inflamasi. Keadaan tersebut sejalan dengan prinsip analgesia preemtif, yaitu pengobatan yang dimulai sebelum pembedahan serta mencegah pembentukan pusat sensitisasi yang disebabkan oleh cedera insisional dan juga inflamasi (meliputi periode operasi dan periode awal pascabedah). ${ }^{3}$

Sebanyak dua dari 33 subjek dari kelompok $P$ diberikan analgetik pertolongan, sedangkan pada kelompok K hanya seorang dari 33 subjek yang mendapatkan analgetik pertolongan. Perbandingan analgetik pertolongan antara kedua kelompok tidak bermakna berdasarkan statistika $(p>0,05)$. Hal tersebut menunjukkan bahwa kedua analgetik yang diberikan samasama memberikan efek analgesia yang cukup untuk tindakan labioplasti pasien pediatrik.

\section{Simpulan}

Pemberian ketorolak $0,5 \mathrm{mg} / \mathrm{kgBB}$ intravena memberikan efek analgesia pre-emtif lebih baik bila dibanding dengan parasetamol 20 $\mathrm{mg} / \mathrm{kgBB}$ intravena dalam mengurangi skala FLACC pascabedah labioplasti pada pasien pediatrik.

\section{Daftar Pustaka}

1. Monitto C, Kost-Byerly S, Yaster M. Pain management. Dalam: Davis PJ, Cladis FP, Motoyama EK, penyunting. Smith's anesthesia for infants and children. Edisi ke-8. Philadelphia: Mosby; 2011. hlm. 419.

2. Voepel-Lewis T, Zanotti J, Dammeyer J, Merkel S. Reliability and validity of the face, legs, activity, cry, consolability behavioral tool in assessing acute pain in critically ill patients. Am J Crit Care. 2010;19(1):5561.

3. Kissin I. Preemptive analgesia. Anesthesiology. 2000;93(4):1138-43.

4. Jahr JS, Lee VK. Perioperative pharmacotherapy intravenous aceta-minophen. Anesthesiol Clin. 2010;28 (4):619-45.

5. Lee $\mathrm{IH}$, Sung C-Y, Han JI, Kim CH, Chung RY. The preemptive analgesic effect of ketorolac and propacetamol for adenotonsillectomy in pediatric patients. Korean J Anesthesiol. 2009;57:308-13.

6. Schendel SA, Shuer LM, Looby JF, Furukawa L, Hammer GB. Cleft lip repair-unilateral/ bilateral. Dalam: Jaffe RA, Samuels SI, Schmiesing CA, Golianu B, penyunting. Anesthesiologist's manual of surgical procedures. Edisi ke-4. Philadelphia: Lippincott Williams \& Wilkins; 2009. hlm. 1407-23. 
7. Lonnqvist PA, Morton N. Post operative analgesia in infants and children. $\mathrm{Br} \mathrm{J}$ Anaesth. 2005;95(1):59-68.

8. Hasani A, Soljakova M. Preemptive analgesia in children with caudal blocks. webmedcentral. 2011 [diunduh 17 Maret 2013];2(3). Tersedia dari: http://www. webmedcentral.com/article_view/1679.

9. Dahl JB, Møiniche S. Pre-emptive analgesia. Br Med Bull. 2004;71:13-27.

10. Bertolini A, Ferrari A, Ottani A, Guerzoni S, Tacchi R, Leone S. Paracetamol: new vistas of an old drug. CNS Drugs Rev. 2006;12(3-
4):250-75.

11. Bonnefont J, Courade J-P, Alloui A, Eschalie A. Mechanism of the antinociceptive effect of paracetamol. Drugs. 2003;63(2):1-4.

12. Cohen MN, Christians U, Henthorn T, Tran ZV, Moll V, Zuk J, dkk. Pharmacokinetics of single-dose intravenous ketorolac in infants aged 2-11 months. Anesth Analg. 2011;112(3):656-60.

13. Kokki H. Nonsteroidal anti-inflammatory drugs for postoperative pain. Pediat Drugs. 2003;5(2):103-23. 